\title{
Beware of the pendulum swing: how leaders can sustain rapid technology innovation beyond the COVID-19 crisis
}

\author{
Eivor Marianne Oborn $\mathbb{C}^{1},{ }^{1}$ Michael lan Barrett, ${ }^{2,3}$ David Alexander Stig Barrett ${ }^{4}$
}

'Warwick Business School, University of Warwick, Coventry, UK

${ }^{2} J u d g e$ Business School, School of Technology, University of Cambridge, Cambridge, UK ${ }^{3}$ Stockholm School of Economics, Stockholm, Sweden ${ }^{4}$ Faculty of Medical Sciences, University College London School of Life and Medical Sciences, London, UK

\section{Correspondence to} Dr Eivor Marianne Oborn, Warwick Business SChool, University of Warwick, Coventry CV4 7AL, UK.

eivor.oborn@wbs.ac.uk

Received 30 May 2020 Revised 4 July 2020

Accepted 6 July 2020

Published Online First 15 July 2020
In the wake of the coronavirus (COVID-19) crisis, we caution against a return to old ways of working and, instead, urge healthcare leaders to consolidate and build on the recently achieved rapid gains in technology adoption. Primary care has been at the forefront, leading the dramatic surge in the use of telemedicine to deliver care through video consultations. $^{12}$ This ability for telemedicine to deliver care at a distance, and with minimal contact, has been termed 'digital personal protective equipment (PPE)'. 3 These successful developments with lifechanging consequences have whet the appetite with possibilities. As the context changes to the new 'normal', there is a growing determination to sustain and embed, rather than return to old ways of working. Although the shift to a care environment where virtual models of healthcare service delivery can be expected to increase, even predominate, the need to allow for human contact will remain an important, if not vital, consideration.

We draw on our technology innovation research and wider scholarship in management to suggest two key strategies to sustain the momentum towards increasingly virtual models of care. First, the need to foster the joining up of care that has recently been catalysed through increased interoperability, data sharing and meaningful use. Second, together working that involves a shared leadership approach to service delivery. Such working towards a shared purpose has been fostered in the recent crisis where leaders sought to restore a sense of collective action, helping everyone realise we are in this together, working towards a common goal.

\section{JOINING UP}

The need for 'joined-up thinking' in healthcare is well established. Healthcare is delivered by a diverse set of stakeholders including primary, secondary and social care as well as those across local, regional and national levels. In addition, many chronic disease management pathways involve patients and families being centrally involved in administering their own care. For innovation and technology to be sustaining, the care across these different stakeholders and organisational contexts needs to facilitate integration rather than fragmentation. ${ }^{45}$ Importantly, governance across different domains (eg, transparency, accountability, participation, integrity and capacity) spanning the health stakeholder context, needs to support, rather than hinder, this integration. ${ }^{6}$ Below, we suggest three key premises for how joining up of care may be achieved.

- Interoperability and business process transformation.

- Consideration of technical and human factors in nudging behaviour change.

- Incentivising data sharing practices to realise benefits.

Interoperability, the ability of technology systems to exchange information, is at the core of an efficient and effective healthcare information infrastructure. ${ }^{7}$ Interoperable systems enable healthcare professionals to deliver timely and quality care to patients. Healthcare IT systems are often patchworked, and this often creates challenges of integration between new technologies and legacy systems. ${ }^{1}$ In pre-COVID-19 times, the differences in accountability between primary and secondary and social care systems may have hampered the shift to the rapid adoption of technology. Application programming interfaces and standards along with appropriate governance rules and mechanisms can help improve linkages and communication and allow for smooth referrals between primary and secondary care systems. Further, interoperability has the potential to extend into the patients' sphere, by connecting to applications on their own devices with which they are familiar. However, although necessary, interoperability is not sufficient for ensuring that joining up is effective in achieving widespread adoption. The embrace of telemedicine and remote working will have longerterm sustainability if accompanied by rethinking the processes around service delivery and enabling business process transformation to improve clinical workflows. Virtual models of care will require new or different steps in the care delivery process. For example, scheduled teleconsultations may now require sending a patient an SMS text alert $5 \mathrm{~min}$ prior to their scheduled appointment, so that they can have their electronic device accessible and open. These new service models of delivering 'contactless' care through teleconsultations can foster a wide range of new opportunities across the health system. ${ }^{8}$ Further, business process rethinking relies on an integrated digital end-to-end approach that spans across levels and sectors, for example, general practitioners (GPs) consulting social care or specialist doctors on patient care in the community. Such an approach is patient centred with a focus on value-adding activities while process ownership and responsibility are made clear. Implementing 
this approach wholeheartedly has implications for clinical roles, workforce training and reconfiguring the delivery of primary health services.

Joining up the care process requires not only attention to technology and systems but also needs due consideration of social and human factors. In particular, we suggest accommodating flexible use, which will enable care providers to improvise effectively in their work. Diverse care providers engage with their patients or service users in different ways, and this has implications for how technology is used. In some contexts, it makes sense to use technology more centrally, whereas in other contexts, it might work better to use technology in a more peripheral manner. Flexible technology use, rather than an expected 'one size fits all' approach, can sustain its wider take up. We suggest, therefore, that joining up care can be facilitated through an integrated digital approach, which also allows for a diversity of technology use. ${ }^{5}$ Diversity in use can be supported by establishing integrity regarding the governance of roles and responsibilities that can clarify expected outcomes while enabling flexibility. Further, beyond the integration of technologies into different care contexts (including GPs, hospitals, social care and patients), due consideration should be given to human factors around behavioural change. Creative ways of nudging users to direct their attention as to how to use technology in their work can promote its meaningful use. Classic clinical nudge behaviours include sending SMS reminders to patients about upcoming appointments or nudging clinicians to prescribe generic drugs. ${ }^{9}{ }^{10}$ Future nudges to promote telemedicine adoption might use artificial intelligence creatively while being mindful of inclusivity.

Finally, we suggest that joining up requires sustaining effective data sharing practices to create value for all organisations and the wider health system. The COVID-19 crisis saw unprecedented volumes of national data sharing, for example, through GP connect and summary care records. In just over a month, 1.1 million records have been populated, almost doubling the previous total. ${ }^{3}$ With more data available, there are more opportunities for improved decision-making. For example, knowing which locations are running out of PPE in a timely manner will help with logistics and supply chain management. Alternatively, knowing which frail person's caregiver has just been admitted to the hospital can inform primary care professionals in maintaining effective care. To incentivise data sharing, all stakeholders need to benefit. A key challenge going forward is to cultivate and promote data sharing behaviours across the system. To do so, specific policies on data practices need to be developed along with appropriate governance structures that include transparency and accountability to avoid data hoarding or illicit use. For example, it may be that raw data are not released; rather the focus may be on agreeing that the rules and procedures for consolidating summary care record data enable decision making or the repurposing of data for healthcare innovation. To facilitate data use and reuse, metadata (ie, description and contextual information on data) needs to be designed for and developed. Effective implementation of data sharing will enable benefits to be realised by individual organisations as well as across the wider health system.

\section{TOGETHER WORKING}

One of the reasons why technology adoption has historically been slow in healthcare is because of its strong institutional forces, the assumptions and norms that govern and guide action, creating stability in the way that doctors work. ${ }^{11}$ During a crisis, there is a collective breakdown of institutional assumptions and shared norms. ${ }^{12} 13$ Thus, during a crisis like COVID-19, old assumptions become less relevant and even formal governance mechanisms and structures are more easily loosened. A key question remains as to what happens to these structures as we enter the 'new normal'. A key role for leaders, therefore, is to quickly frame and manage meaning to engender collective action and restore social order while leveraging new opportunities. Framing the current COVID-19 pandemic as a battle has helped engender a strong sense of solidarity, enabling the many stakeholders to work together. Building on these developments, leaders and front-line workers should foster shared leadership as they respond to emerging needs. To promote this shared leadership for improved service delivery, we suggest three key premises for what has been coined 'together working'.

- Working with clinicians to deliver service through multiple service options for care.

- Walking the user journey in designing for service inclusion.

- Developing an agile mindset in planning transitions for catch up care.

Services will benefit from using technology to deliver care in flexible ways. ${ }^{14}$ Providing care through multiple service options so that there are several ways to access care adds value to the patient and service users. Having multiple service options can enable organisations to build better relationships with their patient or user groups. Rather than working in competition, communication and coordination can be enabled between services. Busy commuters, young mothers and the frail elderly can all benefit from targeted service delivery, specific to their circumstances and needs. Thus, some patients may prefer to continue using telemedicine with their GP, whereas others who enjoy social contact may prefer face-to-face consultations, while yet others coping with mental health issues may prefer telephonebased services. To effectively promote this future scenario, governance around accountability is needed across the breadth of users to help foster adequate flexibility in service provision. The flexibility of care can also bolster benefits to service providers as it gives opportunity for staff to work remotely. Rather than returning to a former way of working, leaders can work with clinicians to maximise the efficiency of multiple modes of service provision, and thereby aim to improve overall care measured through both clinical outcomes and patient experience. ${ }^{15}$

Research on technology adoption in service design points to the ongoing occurrence of unintended consequences to technology use. ${ }^{16}$ One such unintended consequence is that some segments of society may become excluded and less able to access care. As technology changes the way services are delivered, design thinking concepts ${ }^{17}$ would suggest that leaders should be encouraged to walk through the user journey in designing for service inclusion. ${ }^{18}$ With new virtual ways of delivering care, it will be important for leaders to be mindful of excluded groups and design appropriate care alternatives for them. Further governance mechanisms around participation that enable input from across the spectrum of users affected by these potential decisions are important to ensure justice to marginalised groups. Furthermore, appropriate accountability across care sectors is important to prevent perverse incentives from excluding groups, or simply shifting the care of some groups for less appropriate treatments in other parts of the wider system. It is imperative that a digital divide does not lead to a gap in care provision. Designing for inclusion means that those organising care processes understand the journey a patient takes to access care and thereby gain insight into the challenges that confront them. ${ }^{19}$ For example, individuals who are blind, or elderly, or unable to access the internet will have different user journeys. This may likely have important 
implications as to how they might be able to respond in using technology for care provision, and therefore service inclusion.

Together working requires stakeholders to develop an agile mindset in responding and adapting technology use to the evolving situation. An agile mindset entails openness to improvising with technology in solving problems as they arise. Going forward, agile ways of working will be important to maintain. Given the smaller size of most primary care organisations compared with secondary or social care, these organisations may be most likely to maintain their agility. One of the challenges that looms before the health service as a 'new normal' sets in is how to catch up on the backlog of missed appointments, screening, immunisations and routine care that have been set aside to cope with COVID-19. An agile mindset will help in planning this transition, remaining open to using technologies in finding solutions to catch up on 'missed' work, rather than simply reverting to old ways. By maintaining such a mindset, the health system, which is already stressed, will be better equipped to catch up on neglected areas of work and resolving ongoing challenges. However, the health system will also need to maintain its capacity to skilfully monitor the delivery of 'catch up work' in a way that does not stymie improvisation but reinforces safety. Together, working nimbly in leveraging technologies, leaders will be able to accelerate healthcare innovation and foster the new norms of working.

\section{CONCLUSIONS}

We have discussed the importance of strategies that catalyse joining up and together working in sustaining recent momentum towards increasingly virtual models of care. These are important strategies and capabilities for leaders and decision makers to develop so as to resist the pendulum swing back to old ways of working. Joining up foregrounds going beyond care transactions to integrating technical systems and human factors, whereas together working highlights the importance of leadership being shared with those in the front line of care as they respond to emerging needs for service development and delivery. It is important to inspire and cultivate an agile mindset to strengthen leadership at all levels of the health system as well as integrate the appropriate governance approaches and incentives mechanisms across health and social care to support innovation. This is crucial as other factors, such as cost savings, will likely become paramount and may outweigh nudge incentives. In such cases, we may see a reversal of the great gains achieved during the pandemic. A less favourable scenario may be that financial pressures after the pandemic may become even greater leading to a widening in healthcare inequalities as the consequences in different health systems vary depending on their funding model and the unintended impact of the COVID-19 crisis. While the jury is out, what this crisis has reinforced is that virtual models of care are here to stay. Healthcare leaders have the responsibility to understand and develop a wide range of technology-enabled models of care, the need for which has never been greater.

Contributors EO wrote first draft. MB and DB reworked draft in iterations. All authors were involved in final editing.

Funding EO is supported by the National Institute for Health Research (NIHR) Applied Research Centre (ARC) West Midlands. The views expressed are those of the author(s) and not necessarily those of the NIHR or the Department of Health and Social Care.

Competing interests None declared.

Patient consent for publication Not required.

Provenance and peer review Not commissioned; externally peer reviewed.

This article is made freely available for use in accordance with BMJ's website terms and conditions for the duration of the covid-19 pandemic or until otherwise determined by BMJ. You may use, download and print the article for any lawful, non-commercial purpose (including text and data mining) provided that all copyright notices and trade marks are retained.

\section{ORCID iD}

Eivor Marianne Oborn http://orcid.org/0000-0003-0566-4327

\section{REFERENCES}

1 Wherton J, Shaw S, Papoutsi C, et al. Guidance on the introduction and use of video consultations during COVID-19: important lessons from qualitative research. BMJ Leader 2020;4:120-3.

2 NHS England. Advice on how to establish a remote 'total triage' model in general practice using online consultations, 2020. Available: https://www. england. nhs. uk/

3 Nazir M, Parry J. Digital health Webinar, digital first responses to COVID-19 2020; may 1 digital health webinar - 010520 v2.0

4 Ellingsen G, Monteiro E. A patchwork planet integration and cooperation in hospitals. Computer Supported Cooperative Work 2003;12:71-95.

5 Oborn E, Barrett M, Davidson E. Unity in diversity: electronic patient record use in multidisciplinary practice. Information Systems Research 2011;22:547-64.

6 Greer SL, Vasev N, Jarman H, et al. It's the governance, stupid! TAPIC: a governance framework to strengthen decision making and implementation. European Observatory on Health Systems and Policies 2019.

7 Star SL, Ruhleder K. Steps toward an ecology of infrastructure: design and access for large information spaces. Information Systems Research 1996;7:111-34.

8 Armfield NR, Bradford M, Bradford NK. The clinical use of Skype--For which patients, with which problems and in which settings? A snapshot review of the literature. Int J Med Inform 2015:84:737-42.

9 Abraham C, Michie S. A taxonomy of behavior change techniques used in interventions. Health Psychol 2008;27:379-87

10 Thaler RH. Sunstein C: Nudge: improving decisions about health, wealth, and happiness. New Haven: Yale University Press, 2008.

11 Reay T, Hinings CR. Managing the rivalry of competing institutional logics. Organization Studies 2009;30:629-52.

12 Weick KE. The collapse of Sensemaking in organizations: the Mann Gulch disaster. Adm Sci Q 1993;38:628-52.

13 Pearson CM, Clair JA. Reframing crisis management. Acad Manage Rev 1998;23:59-76.

14 Barrett M, Davidson E, Prabhu J, et al. Service innovation in the digital age: key contributions and future directions. MIS Quarterly 2015;39:135-54.

15 Zimlichman E. Telemedicine: why the delay? Isr Med Assoc J 2005;7:525.

16 Berente N, Lyytinen K, Yoo Y, et al. Institutional logics and pluralistic responses to enterprise system implementation: a qualitative meta-analysis. MIS Quarterly 2019:43:873-902.

17 Brown T. Design thinking. Harv Bus Rev 2008;86:84-92.

18 Brown T, Wyatt J. 'Design Thinking for Social Innovation'. Stanford Social Innovation Review 2010;8:30-5.

19 Richardson A. Using customer journey maps to improve customer experience. Harvard bus review, 2010. Available: https://hbr.org/2010/11/using-customer-journey-maps-to/ 